\title{
Pemberdayaan Siswa Madrasah Aliyah Negeri (MAN) 2 Banyumas dalam Upaya Peningkatan Kesehatan Reproduksi dan Pencegahan Penyakit Menular Seksual
}

\author{
Afifah $^{1}$, Rani Afifah Nur Hestiyani², Gema Citra Dwiputranti ${ }^{3}$, \\ Tri Okmawati Handini ${ }^{4}$ \\ 1, 2, 3,4 Universitas Jendral Soedirman
}

\begin{abstract}
ARTICLE INFO
Article History:

Received 14.09.2018

Received in revised

form 15.11.2018

Accepted 03.12.2018

Available online

26.12.2018

ABSTRACT

The incidence of pregnancy without marriage in students tens to increase. About $62.7 \%$ of teenagers in Indonesia have free sex and $21 \%$ who are pregnant have an abortion. About $30 \%$ of HIV-AIDS patients are teenagers. Knowledge of the importance of reproductive health, especially related to the way of transmission of sexually transmitted disease can help adolescents in making decisions of their health. Mandrasah Aliyah Negeri (MAN) 2 Banyumas is one of senior high school in center of city which were their students can access the information from either internet or mass media easely, so the tendency to access negative things that can affect theit actions is very possible. This empowerment was carried out with transfer knowledge, providing modules, leaflet, watch the video, and role play. The subject were 392 students of MAN 2 Banyumas. Pre-test and post-test score analyzed with wilcoxon sign-rank test. There were significant differences in students' knowledge before and after the activity. In conclusion, this program can improve the knowledge of reproductive health and prevent the transmission of sexual transmitted disease in students of MAN 2 Banyumas.

Keywords: Reproductive Health, Sexual Transmitted Disease, Teenagers.
\end{abstract} Commons Attribution 4.0 International License, which permits unrestricted use, distribution, and reproduction in any medium, provided the original work is properly cited. (־ 2018 Afifah, Rani Afifah Nur Hestiyani, Gema Citra Dwiputranti, Tri Okmawati Handini.

\section{PENDAHULUAN}

Kesehatan reproduksi merupakan keadaan sehat secara fisik, mental, dan sosial secara utuh, tidak semata-mata bebas dari penyakit atau kecacatan yang berkaitan dengan fungsi, dan proses reproduksi (WHO, 2014). Kesehatan reproduksi remaja merupakan salah satu ruang lingkup pelayanan kesehatan reproduksi menurut International Conference Population and Development (ICPD). Menurut Peraturan Menteri Kesehatan RI Nomor 25 tahun 2014, remaja adalah penduduk dalam rentang usia 10-18 tahun. Remaja 
merupakan periode terjadinya tumbuh kembang yang pesat baik fisik, intelektual, maupun psikologis. Sifat khas remaja yaitu mempunyai rasa ingin tahu yang besar, menyukai petualangan dan tantangan serta cenderung berani menanggung risiko atas tindakannya tanpa melalui pertimbangan yang matang (Kementerian Kesehatan RI, 2015).

Angka kejadian kehamilan diluar nikah pada remaja cenderung meningkat dari tahun ke tahun. Salah satu penyebab terjadinya peningkatan tersebut diakibatkan oleh adanya efek negatif perkembangan IPTEK khususnya media sosial yang sangat cepat dan mudah diakses (Derese, Seme, \& Misganaw, 2014). Badan Kependudukan dan Keluarga Berencana Nasional (BKKBN) menyatakan bahwa angka kelahiran pada kalangan remaja puteri masih tinggi sekitar 48 per 1.000 perempuan usia 15 - 19 tahun. Survei oleh KPAI dan Kemenkes Tahun 2013 menyebutkan bahwa 62,7\% remaja di Indonesia melakukan seks di luar nikah, 21\% dari jumlah remaja yang hamil di luar nikah melakukan aborsi sedangkan 30\% penderita HIV AIDS adalah remaja (BKKBN, 2014; Jatmiko., et al., 2009; Dily, Makes, \& Zubier, 2009).

Pengetahuan mengenai pentingnya kesehatan reproduksi terutama berkaitan dengan cara penularan penyakit menular seksual dapat membantu remaja dalam mengambil keputusan apakah mereka akan melakukan tindakan yang sehat atau tidak sehat terhadap dirinya terutama berkaitan dengan kesehatan reproduksi. Begitu juga sebaliknya, informasi yang salah mengakibatkan kesalahan persepsi dan menimbulkan perilaku negatif terhadap kesehatan reproduksi terutama berkaitan dengan penularan penyakit menular seksual (Kumalasari dan Andhyantoro, 2012). Pemahaman tentang seksual yang dianggap tabu oleh masyakarat dan adanya mitos-mitos yang salah tentang seksual, menyebabkan pemahaman remaja mengenai pengetahuan seksualitas masih rendah. Hal ini dibuktikan dengan tingginya angka kejadian seks bebas (Nurlaela, 2008). Remaja usia sekolah khususnya tingkat SMA merupakan remaja yang sedang mencari jati diri dan mempunyai rasa ingin tahu yang tinggi. Mereka cenderung lebih suka berkumpul dengan teman-teman sebanyaknya dan melakukan hal-hal yang menyenangkan tanpa memikirkan efek negatif yang dapat ditimbulkan. Padahal seharusnya mereka mulai mempersiapkan diri untuk nantinya menjadi ayah atau ibu bagi anak-anaknya. Agar dapat melahirkan anak-anak yang sehat, seorang calon ayah dan calon ibu harus mempunyai kesehatan reproduksi yang sehat (Kementerian Kesehatan RI, 2015).

Madrasah Aliyah Negeri (MAN) 2 Banyumas merupakan salah satu sekolah tingkat SMA dengan jumlah siswa kurang lebih 1200 dari 3 kelas yaitu kelas X, XI, dan XII. Kelas $X$ dan XI masing-masing sebanyak 10 kelas dan setiap kelas berjumlah sekitar 40 orang. MAN 2 Banyumas terletak di tengah kota dimana akses informasi baik melalui internet, surat kabar atau media lainnya sangat mudah didapatkan, sehingga kecenderungan untuk mengakses hal-hal negatif yang dapat mempengaruhi tindakan mereka sangat mungkin dilakukan. Sehingga dapat mengakibatkan dampak negatif bagi dirinya terutama berkaitan dengan organ reproduksi dan penularan penyakit menular seksual.

Sebagai tenaga pendidik di bidang kedokteran yang memahami ilmu reproduksi dan kesehatan remaja, kami terpanggil untuk melakukan suatu kegiatan yang diharapkan mampu berkontribusi meningkatkan kesehatan reproduksi dan menurunkan kejadian penyakit menular seksual (PMS) di kalangan remaja usia sekolah khususnya Sekolah Menengah Atas (SMA). 


\section{METODE PELAKSANAAN}

Kegiatan pemberdayaan siswa-siswi MAN 2 Banyumas dalam upaya peningkatan kesehatan reproduksi dan pencegahan penyakit menular seksual dilakukan dengan pemberian materi (penyuluhan), pemutaran video, pemberian modul, leaflet, serta bermain peran (role play). Subyek kegiatan yaitu siswa-siswi MAN 2 Banyumas kelas X dan XI sejumlah 392 orang. Materi yang diberikan mengenai kesehatan reproduksi, pentingnya menjaga kesehatan reproduksi, penyakit infeksi menular seksual yang meliputi jenis, penularan, akibat, komplikasi, serta pencegahannya. Selama pemberian materi, siswa-siswa diajak untuk berdiskusi mengenai topik yang disampaikan dan sesekali diberikan pertanyaan untuk mengetahui apakah mengerti dengan materi yang dusampaikan. Setelah sesi pemberian materi, dilanjutkan dengan pemutaran film mengenai kesehatan reproduksi dan infeksi menular seksual.

Modul dan leaflet berisi informasi mengenai kesehatan reproduksi dan infeksi menular seksual diberikan kepada siswa-siswi untuk dapat dibaca guna menambah pemahaman dan dijadikan referensi ketika menyampaikan kepada orang lain. Setelah pemtaran film disediakan waktu khusus untuk diskusi. Kegiatan terakhir yaitu bermain peran atau dikenal dengan istilah role play untuk menyampaikan informasi kepada teman lain. Kegiatan bermain peran ini lakukan oleh perwakilan siswa secara berpasangan ( 2 orang) kemudian 1 siswa berperan sebagai yang pemberi informasi, dan yang lain sebagai penerima informasi sesuai skenario yang diberikan.

Sebelum kegiatan dimulai, terlebih dahulu peserta diberikan soal pre-test guna mengetahui tingkat pengetahuan awal, dan diakhir kegiatan diberikan soal post-test. Post-test diberikan untuk mengukur tingkat pemahaman siswa-siswi peserta kegiatan setelah melalui seluruh rangkaian kegiatan. Nilai hasil pre-test dan post-test dihitung reratanya, dan dianalisis menggunakan Wilcoxon sign-rank test, dengan tingkat kemaknaan yang signifikan $\mathrm{p}<0,05$.

\section{HASIL DAN PEMBAHASAN}

Subyek kegiatan ini sebanyak 392 orang yang terdiri dari siswa-siswi MAN 2 Banyumas Kelas X dan XI. Semua mengisi lembar jawaban pre-test dan post-test. Rerata nilai pre-test dan post-test dapat dilihat pada Gambar 1.

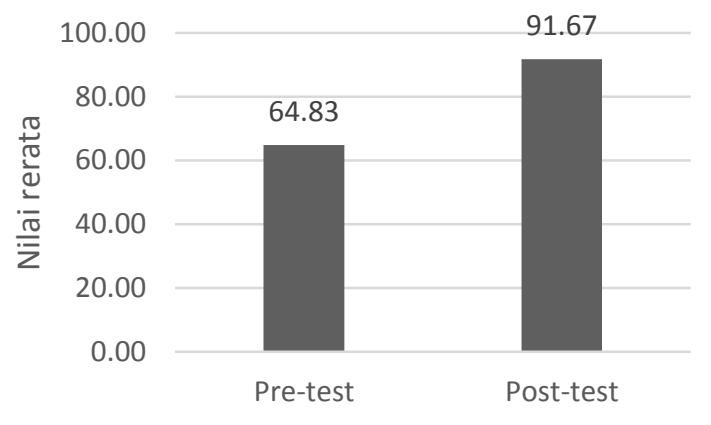

Gambar 1. Rerata Nilai Pre-test dan Post-test

Pada Gambar 1 dapat dilihat rerata nilai pre-test dan post-test yaitu rerata nilai pretest 64,83 dan rerata nilai post-test 91,67. Hasil analisis statistik dilakukan untuk mengetahui adakah terdapat perbedaan yang signifikan antara sebelum dan sesudah mengikuti kegiatan. Hasil analisis statistik dapat dilihat pada Tabel 1. 
Tabel 1. Nilai Pre-test dan post-test

\begin{tabular}{llll}
\hline Jumlah Siswa (n) & $\begin{array}{l}\text { Rerata Nilai } \\
\text { Pre-test }\end{array}$ & $\begin{array}{l}\text { Rerata Nilai } \\
\text { Post-test }\end{array}$ & p (Uji Wilcoxon) \\
\hline 392 & 64,83 & 91,67 & 0,000 \\
\hline
\end{tabular}

Untuk mengetahui apakah terdapat perbedaan pengetahuan sebelum dan sesudah mengikuti kegiatan dilakukan uji t-berpasangan. Sebelum dilakukan uji t berpasangan dilakukan uji normalitas data. Uji normalitas digunakan Kolmogorov-smirnov karena jumlah subjek lebih dari 50 untuk mengetahui distribusi data. Berdasarkan hasil uji Kolmogorov-smirnov didapatkan nilai $\mathrm{p}<0,05$, yang menunjukkan bahwa data tidak terdistribusi normal. Oleh karena data tidak terdistribusi normal maka tidak dapat dilakukan uji t-berpasangan, sehingga dilakukan uji alternatifnya yaitu Wilcoxon sign-rank test. Berdasarkan hasil uji Wilcoxon sign-rank test, didapatkan nilai $\mathrm{p}<0,05$. Hal itu menunjukkan bahwa terdapat perbedaan yang signifikan antara sebelum dan sesudah mengikuti rangkaian kegiatan.

Berdasarkan hasil yang diperoleh, terdapat peningkatan pengetahuan siswa-siswi MAN 2 Banyumas setelah dilakukan penyuluhan, pemutaran video, pemberian modul dan leaflet serta mengikuti role play dalam upaya meningkatkan pemahaman mengenai kesehatan reproduksi dan pencegahan penyakit infeksi menular seksual.

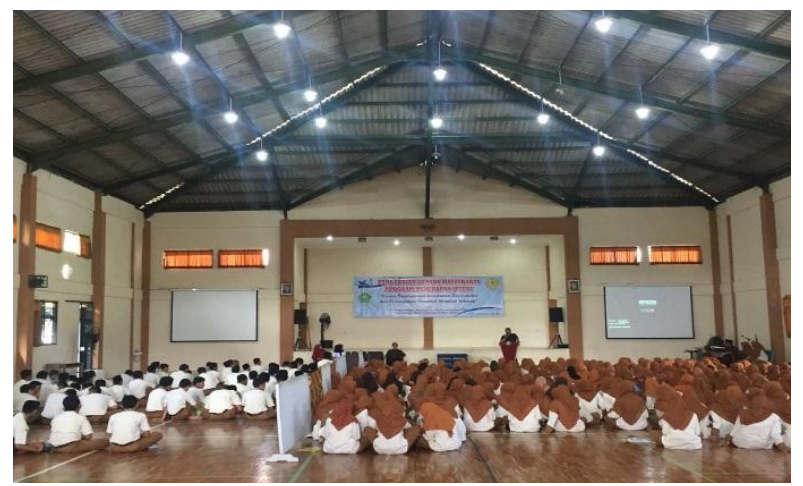

Gambar 2. Pembukaan acara oleh Kepala Madrasah Aliyah Negeri (MAN) 2 Banyumas

Menurut Notoatmojo (2012), perilaku yang didasari dengan pengetahuan akan lebih langgeng dibandingkan dengan perilaku yang tidak didasari oleh pengetahuan. Terlebih lagi pada kegiatan ini dilakukan praktek bermain peran untuk menyampaikan informasi kepada orang lain.

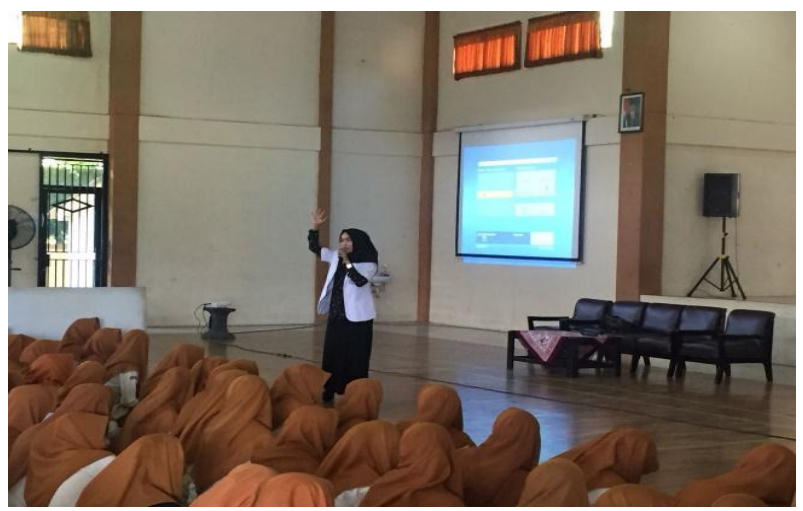

Gambar 3. Pemberian Materi oleh Tim 
Hal itu dapat meningkatkan serapan dan pemahaman mengenai materi yang disampaikan. Beberapa faktor yang mempengaruhi pengetahuan remaja tentang kesehatan reproduksi yaitu informasi, media massa, pengaruh orang terdekat, orang tua, teman dan kegiatan diskusi (Putriani, 2010).

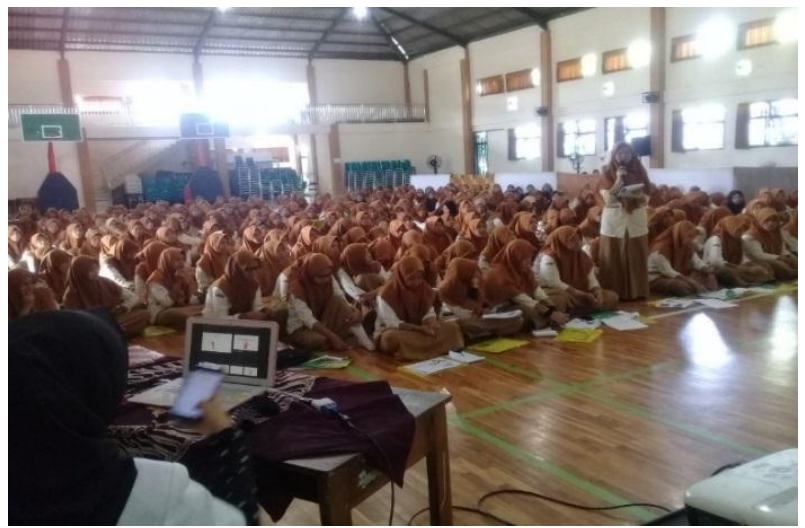

Gambar 4. Sesi Diskusi

Menurut Uno Hamzah (2008) dalam Prastianingsih (2010) mengatakan bahwa bermain peran (role play) adalah suatu metode pembelajaran yang bertujuan untuk membantu siswa menemukan makna diri di dunia sosial dan memecahkan dilema dengan bantuan kelompok. Peran (role) dapat diartikan sebagai cara seseorang berperilaku dalam posisi dan situasi tertentu. Role play sebagai suatu metode mengajar merupakan tindakan yang dilakukan secara sadar dan diskusi tentang peran di dalam kelompok. Metode bermain peran menurut Maulana (2009) digunakan dalam kondisi antara lain yaitu bertujuan membantu peserta memahami suatu masalah, ingin mencoba mengubah sikap peserta, digunakan untuk pemecahan masalah. Tujuan bermain peran antara lain yaitu belajar dengan manyampaikan pendapat, belajar dengan berbuat, belajar dengan meniru, belajar melalui pengkajian, penilaian, dan pengulangan. Pada akhirnya akan membantu seseorang untuk memikirkan kembali sikap dan norma yang selama ini dianut.

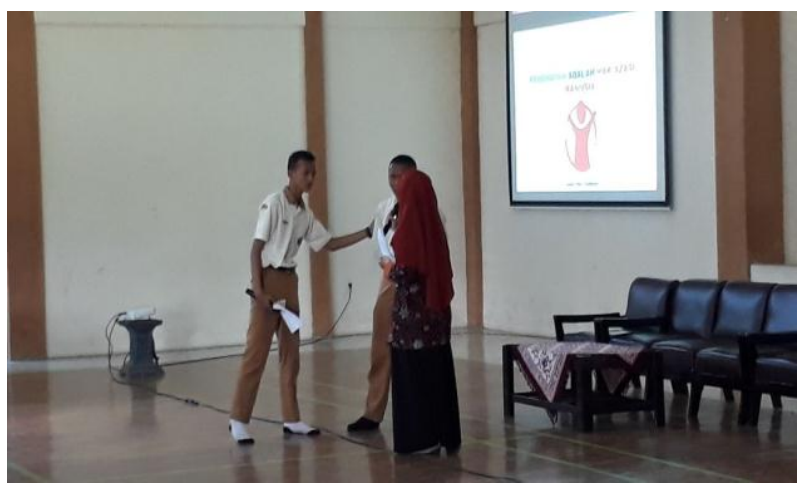

Gambar 5. Bermain Peran (Role Play)

\section{SIMPULAN}

Upaya peningkatan kesehatan reproduksi dan pencegahan penyakit menular seksual pada siswa-siswi MAN 2 Banyumas dapat terlaksana melalui kegiatan pengabdian masyarakat ini. Setelah terselenggaranya kegiatan ini, siswa-siswi MAN 2 
Banyumas mempunyai pengetahuan dan pemahaman yang lebih baik mengenai kesehatan reproduksi dan pencegahan penyakit menular seksual. Selanjutnya siswa-siswi dapat mempraktikkan pengetahuannya serta menyampaikannya kepada orang lain mengenai pengetahuan yang sudah didapat pada kegiatan ini.

\section{UCAPAN TERIMA KASIH}

Penulis mengucapkan terimakasih kepada Lembaga Penelitian dan Pengabdian Kepada Masyarakat, Universitas Jenderal Soedirman, Purwokerto yang telah mendanai kegiatan pengabdian kepada masyarakat ini. Ucapan terima kasih juga kami sampaikan kepada MAN 2 Banyumas sebagai mitra pelaksanaan kegiatan ini sehingga kegiatan ini dapat terlaksana dengan baik dan lancar.

\section{REFERENSI}

BKKBN. (2014). Survei indikator kinerja RPJMN program kependudukan dan keluarga berencana tahun 2014. Jakarta: BKKBN Puslitbang KBKS

Derese, A., Seme, A., \& Misganaw, C. (2014). Assessment of substance use and risky sexual behaviour among Haramaya University Students, Ethiopia. Science Journal of Public Health, 2(2), 102-110.

Dily, S. F., Makes W. I., Zubier F. (2009). Infeksi menular seksual. Jakarta: Balai Penerbit FKUI.

Jatmiko, A. C., Nurharini, F., Dewi, D. K., \& Murtiastutik, D. (2009). Penderita herpes genitalis di divisi infeksi menular seksual unitunit rawat jalan kesehatan kulit dan kelamin RSUD Dr. Soetomo Surabaya periode 2005-2007. Berkala Ilmu Kesehatan Kulit dan Kelamin 21(2), 102-107.

Kemenkes RI. (2015). Situasi kesehatan reproduksi. Jakarta: Infodatin.

Kumalasari, I., \& Andhyantoro, I. (2012). Kesehatan reproduksi untuk mahasiswa kebidanan dan keperawatan. Jakarta: Salemba Medika

Maulana, H. D. J. (2009). Promosi kesehatan. Jakarta: EGC.

Notoatmodjo, S. (2012). Promosi kesehatan. Jakarta. Balai Penerbit FKUI.

Nurlaila. (2008). Hubungan antara penyakit menular seksual dengan sikap seksual pranikah pada mahasiswa semester II Fikkes Unimus. Semarang: Universitas Muhammadiyah Semarang

Putriani, N. (2010). Faktor-faktor yang memengaruhi pengetahuan remaja tentang kesehatan reproduksi di SMA Negeri 1 Mojogedang. (Skripsi, Universitas Diponegoro, Semarang).

Prastianingsih. (2010). Efektivitas metode bermain peran untuk meningkatkan pengetahuan tentang flu burung pada siswa kelas $V$ Sekolah Dasar Negeri Madukara Kecamatan Madukara Kabupaten Banjarnegara tahun ajaran 2009/2010. (Skripsi, Universitas Negeri Semarang).

WHO. (2014). Reproductive health. Jenewa: World Health Organization. 